\title{
Sexo virtual ou virtualidade do sexo?
}

Ana Cristina Canosa Gonçalves*

Em outubro de 1999, a Internet fez 30 anos. Claro que como a conhecemos hoje, com músicas, vídeos, chats, animações e velocidade é coisa de poucos anos. A Internet teve muitos "pais", muitos momentos importantes, mas só na segunda metade da década de 90 é que saiu da redoma universitária para ganhar o interesse do grande público e dos empresários que começaram a vislumbrar na Rede um novo centro de negócios.

Se os usuários iniciantes decoravam comandos enormes para executar os programas das primeiras gerações de chats e levavam horas para conseguir uma conexão, hoje em segundos podemos, por exemplo, visitar um site de um Hotel da África, observar como se comporta o trânsito em determinada via de São Paulo, assistir a um streep-tease feminino transmitido em tempo real, pelo computador, como se fosse na TV, conversar com um amigo tailandês através de um programa particular de chat (ICQ), e ainda se quisermos fazemos tudo ao mesmo tempo, sem sair de casa, do trabalho, ou do ambiente no qual o computador está "plugado" nesta Rede maior de interligações de computadores.

* Psícologa clínica e educadora sexual. Coordenadora do semestre de educação sexual do Curso de pós-graduação em Educação Sexual da SBRASH.

Recebido em 10.10.99

Aprovado em 25.10.99 
A Internet está cada vez mais acessível já que os computadores, as linhas telefônicas e os provedores de acesso tem barateado os seus custos no Brasil. Atualmente os números são contados em milhões e crescem progressivamente, por segundo. São milhões de usuários, milhões de sites, milhares de provedores, milhares de servidores de busca, bilhões de links, etc., etc. Segundo pesquisa da Datafolha, em setembro de 1999 éramos um total de 7,6 milhões de brasileiros com mais de 14 anos acessando a Internet. Para 2000 a mesma pesquisa estima o número de 318,6 milhões de usuários no mundo todo, cerca de $5 \%$ da humanidade (Folha de S. Paulo - caderno 2 - Informática - 20 de outubro de 1999). Acompanhando também este crescimento, atualmente são milhões os sites que envolvem imagens, palavras e animações de cunho erótico, e portanto a cada dia crescem as possibilidades de se encontrar na Internet todos os tipos de práticas sexuais, de serviços sexuais, de troca de mensagens sexuais.

Diante dessa realidade e dos números que se apresentam, nós profissionais da saúde e educação envolvidos com os estudo da sexualidade humana, não podemos resistir em aceitar o fato de que a Internet é uma revolução no que tange a comunicação e ao acesso rápido as informações globalizadas de toda a ordem. A adoção da Internet no cotidiano das pessoas tem aberto novos campos de trabalho, modificado hábitos na escrita, na linguagem, na mobilização e no contato do indivíduo para com seu semelhante. Desta feita, como a sexualidade faz parte do universo humano, o sexo virtual deve ser objeto de estudo minucioso, já que podemos estar diante de um fenômeno de revolução também sexual. Mas para compreendermos como a Internet está influenciando a sexualidade das pessoas (e se está), nossa primeira indagação deve ser: "o que é sexo virtual"?

\section{O SEXO VIRTUAL}

A agência estado divulgou nota jornalística em seus site (08/04/1999) que "cerca de 4,6 milhões de usuários da Internet são viciados em sexo virtual e quase 9 milhões freqüentam sites e chats eróticos na rede". Os dados foram apresentados pelo médico norte-americano Alvin Cooper que pesquisou durante 3 semanas os hábitos dos internautas e concluiu que cerca de 4,6 milhões de usuários da Internet são viciados em sexo virtual e quase 9 milhões freqüentam sites e chats eróticos na rede. Ele diz que 8,5\% dos participantes da pesquisa visita sites eróticos por mais de onze horas semanais.

Certamente um número elevado de horas que um indivíduo despende "navegando" na Internet por dia (mais de 3 horas/dia), quando está em seu período de descanso, convívio com amigos e/ou familiares ou nos seus momentos destinados ao lazer, é indício que algo está errado. A Folhateen de 13 de março de 2000 editou matéria sobre o comportamento compulsivo na 
Internet, que já foi estudado nos EUA e é conhecido como "Internet Addiction Disorder" que inclui sintomas como substituição de atividades sociais pelo uso da Internet, fantasias ou sonhos sobre a Rede e até mesmo reações físicas, como movimento involuntários dos dedos, simulando a digitação. Esta compulsão pode não ser focalizada em apenas um interesse, mas também referir-se ao uso da Internet com fins específicos. Os viciados em "sexo virtual" nos moldes do Dr. Cooper já se manifestam no Brasil, e alguns terapeutas sexuais tem recebido em seus consultórios pessoas que só obtém prazer se estiverem diante do computador fazendo "sexo virtual" com outra pessoa plugada na rede em alguns desses programas de batepapo (chat) disponíveis na Web.

Parece que muito embora o temo sexo virtual seja muito utilizado, ele ainda é largo, plástico, abarca uma série de atividades que tem como ponto de similaridade ter como veículo o computador plugado na Internet $\mathrm{e}$ um objetivo, uma meta que é o sexo genital, visualizado através de imagens pelo acesso de sites eróticos ou ainda pela troca de mensagens entre pessoas que sugerem um encontro sexual. Embora nos pareça que há uma diferença entre acessar um site erótico como alternativa a filmes ou revistas pornográficas, com objetivo de estímulo visual para a excitação, e trocar mensagens que sugerem aproximação sexual genital com uma outra pessoa que está do outro lado da tela, pode ser que em ambos os casos a finalidade, em último plano seja a mesma. Para quantas pessoas a máquina está substituindo o homem no que diz respeito ao vínculo que este faz com seus semelhantes e portanto pouco importa quem ou o quê esteja do outro da linha? E se no percurso da busca da alternativa erotizada eu me interesso pelo 'papo' do outro e marco um "encontro real"? Depende da meta de cada um?

A palavra virtual está estreitamente vinculada a linguagem cibernética e tem uma conotação do que "não é real". Muito embora o "lugar" da Internet seja um lugar concreto inexistente, de alguma forma este lugar foi construído, foi freqüentado, e neste espaço informações são trocadas, "acessadas"; e daí a idéia de que este ambiente pode ser tocado. Pessoas se encontram neste espaço, em tempo real, cada qual de seu computador, independente de onde estejam, de um lado ou outro do planeta. Dia ou noite são, no espaço virtual, um mesmo horário para todos. Este diferencial talvez seja o que impele as pessoas a fazer uma distinção entre o "virtual" e o real. Em questão de comportamento e relacionamento afetivo-sexual, viés de nosso interesse neste texto, é comum os internautas se referirem as pessoas que conhecem pela Internet através da troca de $e$-mails, fóruns de discussões, chats de bate-papo, etc., como "meu amigo virtual", "meu namorado virtual" e até "meu amante virtual". Interessante é que quando alguém que se conheceu online posteriormente encontrou essa pessoa no dia-a-dia, este passa a ser um "amigo real"... Mas esta é sem dúvida mais uma questão que coloco aqui: Poderíamos chamar de "não existente" um relacionamento onde duas pessoas trocam mensagens de afeto, cada qual em seu espaço, ao 
mesmo tempo, durante semanas, meses ou até anos, porque nunca se viram nem se tocaram cara-a-cara? Até que limite nós vamos traçar para legitimar um relacionamento baseado no encontro do "ciberespaço", se o próprio ciberespaço é lugar da cibercultura que prevê a universalidade a falta de monopólio, o acesso irrestrito, uma espécie de "democracia cibernética". No lugar da biodiversidade pela primeira vez o homem pode travar contato com uma variedade tão grande de pessoas no mesmo ambiente, no lugar virtual. Isto sem dúvida é realidade. Ou seria virtualidade?

Estas são questões que podemos e devemos discutir, que nos levam a hipotetizar conclusões e por vezes arriscar algumas previsões, mas que não encontram ainda respaldo científico pela precocidade dos estudos que estão em andamento. Nós mesmos estamos, com o apoio da Sociedade Brasileira de Sexualidade Humana (SBRASH) desenvolvendo pesquisa na área que objetiva avaliar como a sexualidade está se "ajustando" aos progressos da tecnologia, se a Internet aproxima ou distancia as pessoas, se auxilia como estímulo para as fantasias sexuais ou aprisiona os indivíduos em uma única prática sexual que se torna empobrecida na medida em que limita o encontro amoroso corporal, ao nosso ver dos mais enriquecedores. Enquanto nossos estudos e outros não vierem lançar luz à denominação das diferentes práticas sexuais possíveis que ocorrem no espaço virtual, então no momento não há outra alternativa do que tomar como referência ainda o amplo conceito da expressão sexo virtual.

\section{A VIRTUALIDADE DO SEXO}

Ainda analisando a palavra virtual, na língua portuguesa encontramos o seguinte significado: que existe como faculdade, porém sem efeito atual, suscetível de realizar-se, potencial (Ferreira, 1993). Tem conotação de algo que está por concretizar-se e em algum nível já é existente. Há uma potencialidade neste virtual e potencial pode ter duplo entendimento: algo que passa pelo âmbito da possibilidade e outro da ordem da força, da capacidade, da potência. Sendo assim pensamos que nosso sexo virtual é provido de possibilidades e capacidades distintas.

Seguindo concepções teóricas da psicanálise freudiana, a sexualidade humana se apoia na função reprodutiva mas agrega a ela, desde o início da vida, a descoberta dos prazeres corporais. A pulsão sexual, energia psíquica que encontra no biológico sua origem, "pressiona" o organismo e o impele a buscar satisfação. Como no início da vida humana a genitalidade tem de ser adiada até o amadurecimento corpóreo, a pulsão sexual satisfaz-se apoiada na saciação das pulsões de autopreservação. Sendo assim, desde cedo o bebê humano vai descobrindo prazeres e sensações com a estimulação de órgãos como a boca, língua, mãos, ânus, etc. Ao ser alimentado descobre a sensação de estímulo da boca e regiões circunvizinhas, grava na memória 
cheiros, texturas e gestos destes momentos. A pulsão sexual portanto perpassa os limites de sua atuação reprodutiva ou do prazer genital. Está por trás das impressões, do início das conexões imaginárias, da cognição, dos traços de memória, da exploração das percepções dos órgãos do sentido. A pulsão sexual é portanto potencial, tanto em suas faculdades, quando o organismo busca sua satisfação, quanto em sua potencialidade, sua força em manter o organismo em constante busca de prazer aliviando a tensão que provoca o desprazer.

Prosseguindo com este pressuposto o sexo, ou mais precisamente a sexualidade per si já tem seu quinhão virtual. A satisfação do prazer sexual tem tantas possibilidades que é impossível até prever sua finitude. A exploração do corpo como um corpo erótico ou erotizável é potencialmente enorme. Todas as imagens, fantasias, gostos, desejos, toques formam uma trama, uma Rede de conexões que "plugam" o sujeito a busca de seu objeto de desejo. A pulsão busca, o sujeito acessa seu arsenal e a satisfaz de alguma maneira.

É como se o espaço da Internet possibilitasse que o indivíduo "acessasse" núcleos de sua própria personalidade, que estão ali, mas que ainda não se apresentaram no plano da realidade. Não é a toa que o termo para caracterizar a entrada na Internet é acesso. E este ingresso é de livre ação do sujeito. Uma vez online eu acesso o site que quiser, escolho como e por onde vou querer "navegar". Este um outro termo interessante para nossa análise. Faz alusão à percorrer, viajar, seguir viagem e freqüentemente é associado a viagem sobre as águas, céus ou espaço. Na leitura simbólica de histórias infantis e sonhos, a psicologia junguiana e também a psicanálise associa florestas, céus e mares como representantes do inconsciente. São "lugares" que transmitem a sensação de desconhecido, algo inatingíveis, infinitos, onde habitam animais primitivos, por vezes ferozes, que se distinguem do homem por sua natureza instintiva. Ora, uma discussão freqüente na teoria psicanalítica de Freud é justamente a tradução do termo pulsão (trieb em alemão) e instinto (instinct) (Hans, 1999). Na verdade a diferença se coloca mais em relação ao nascedouro da energia sexual; instinto poderia envolver a genética, a hereditariedade, a função humana; pulsão seria algo mais individual, desvinculado da função genética. De qualquer forma, pulsão sexual e instinto estão próximos e por vezes na teoria freudiana são colocados na mesma trama enfática. Minha intenção é dar ao termo "navegar" mais uma proximidade a simbologia do inconsciente já que é neste compartimento de nosso aparelho psíquico que nossa pulsão sexual guardou registros prazerosos que se traduzem em desejos. Navegar simbolicamente seria poder "acessar" este inconsciente, passear por ele, entrar em contato com toda a sua potencialidade, com sua virtualidade.

Talvez por isso a Internet seja tão atrativa aos olhos de seus "navegantes". Sem deter-me na questão da possibilidade de acesso rápido a in- 
formação de toda ordem, existe na Rede um certo estímulo ao exercício da liberdade de ingresso as nossas faculdades. Estas vão além das sexuais, perpassam as cognitivas (inteligência, raciocínio), as que envolvem a psicomotricidade e órgãos dos sentidos: tato, visão, etc., as que compreendem a capacidade criativa e aquelas destinadas as sensações e emoções. Assim sendo, posso ter despertado através do uso da Internet minhas habilidades para a escrita, para o aprendizado de língua estrangeira, posso desenvolver minha criatividade quando "construo" uma homepage ou site, estimular a memorização para reter informações, aprimorar digitação e também, por exemplo, explorar minhas fantasias sexuais através da troca de mensagens eróticas com outro usuário. Desenvolver esta ou aquela característica só é possível porque cada um de nós já possui as faculdades individuais, corporais e mentais que encontram, na Internet a potencialidade em desenvolver-se.

No início do século XX Freud postulava que freqüentemente nós trocamos o alvo sexual originário por outro, na tentativa de apaziguarmos a pulsão sexual impelente, circundante e presente, já que o alvo originário seria por nós tido como indisponível. Em alguns casos este mecanismo se dá, segundo ele, por intermédio dos processos intelectuais e criativos: $A$ pulsão sexual põe à disposição do trabalho cultural quantidades de força extraordinariamente grandes, e isto graças à particularidade, especialmente acentuada nela, de poder deslocar o seu alvo sem perder, quanto ao essencial, a sua intensidade. Chama-se esta capacidade de trocar o alvo sexual originário por outro alvo, que no é sexual mas que psiquicamente se aparenta com ele, capacidade de sublimação (Laplanche; Pontalis, 1986). Fico indagando se este conceito freudiano de sublimação não poderia ser aqui aplicado a nossa reflexão, quando pensamos que a pulsão sexual pode estar agregada aos mecanismos intelectuais que constróem frases digitadas durante as conversas virtuais, como se contos eróticos estivessem sendo escritos pelos internautas. Nesse sentido o material sublimado está na palavra, revelando a potencialidade dos nossos mecanismos psíquicos para satisfazerem o alvo sexual originário.

Em uma sociedade fruto da repressão sexual que violou e por vezes bloqueou a satisfação de nossas pulsões sexuais por intermédio da cultura (e só por causa desse recalque a cultura pôde promover-se), ter acesso livre para navegar nos espaços sexuados é dar ao sujeito forma de entrar em contato com aquilo que em si mesmo é potencial e que por tempos esteve reprimido. É o que eu chamo de virtualidade do sexo. Fazemos esta ponte porque é realidade que muitos usuários apresentam interesse pelos assuntos ligados à sexualidade na Internet. Parece que o acesso a um site erótico ou chat do mesmo cunho é no mínimo curiosidade geral. Em nosso estudo, dos 60 pesquisados até o momento $57 \%$ (95\%) já entrou ou entra rotineiramente em uma sala de sexo virtual. 
Uma vez online o internauta pode navegar em sites eróticos de práticas sexuais específicas, pode buscar contato sem necessidade de identificação com pessoas que tenham preferências semelhantes, pode dar vazão a virtualidade de sua energia sexual. Tem sido comum o relato dos usuários que freqüentam salas destinadas ao "sexo virtual" quando dizem se masturbar diante do computador durante suas conversas. Outros navegam por espaços comunitários objetivando, por vezes de forma inconsciente, saciar um desejo de encontro, uma fantasia de par, uma necessidade de afeto. Esta é sem dúvida uma vertente potencialmente forte da sexualidade virtual, o encontro amoroso que se dá online.

\section{SEXO VIRTUAL OU VIRTUALIDADE DO SEXO?}

Muitos internautas se "apaixonam" por pessoas que em um primeiro momento nunca se viram. Esta aproximação, que se dá através do uso da palavra escrita que é talvez a segunda forma de comunicação mais antiga da humanidade (sendo a primeira a linguagem verbal) é legítima como forma de sedução. No entanto é no mínimo curioso que, em uma sociedade como a nossa, que infelizmente estimula o "ter" e não o "ser", que eleva os padrões de beleza física em detrimento dos valores de caráter, que a atração pelo olhar, o (re)conhecimento da imagem corporal seja substituído apenas pelas frases que se apresentam na tela do computador. Porém a palavra escrita parece que tornou-se insuficiente para traduzir emoções. Símbolos foram criados para expressar sentimentos durante as relações virtuais. São as chamadas caracteretas, smiley ou ainda emoticons. Assim como exemplo: :-) significa riso; :-( tristeza; :-p mostrar a língua; ;-) piscar o olho, etc.

Quando o acesso aos chats tornou-se "moda" no Brasil, nos idos de 1997, a preocupação dos profissionais ligados à educação, saúde e comportamento era, sem dúvida, que esta forma de relacionamento fosse demasiada pautada na fantasia e substituísse a possibilidade concreta de relacionamento afetivo. Temos visto isto ocorrer em alguns casos, principalmente naqueles onde as pessoas encontram na Internet uma forma protegida para relacionar-se. Ela não se expõe, não se mostra, não arrisca ter sua imagem corporal e comportamental avaliada pelo outro. Tem medo de ser rejeitada, de não ser amada e diminuir ainda mais uma auto-estima já abalada. Da mesma forma prefere fantasiar a imagem do outro, idealizar um contato e convívio perfeito, uma história que por medo o indivíduo afasta o cotidiano e a realidade de minar.

No entanto para nosso alívio há alguns indícios que estes casos são a minoria. O desenvolvimento tecnológico tem demonstrado que há necessidade do reconhecimento visual do outro, da proximidade com a imagem e $o$ som. As videocams instaladas nos computadores possibilitam que as figuras dos internautas sejam projetadas nas telas dos monitores viabilizando o 
reconhecimento visual. Alguns outros programas de som permitem que, além da digitação, os usuários possam ouvir a voz do outro com quem estão conversando. De certo, se o mercado da informática está aprimorando e comercializando tais programas e acessórios, então podemos supor que a busca pelo reconhecimento do outro, da proximidade com o "real" resiste aos atrativos fantasiosos e ideais de um contato estritamente virtual. Embora nossos dados ainda sejam insuficientes para conclusões mais precisas, dos 21 pesquisados que relataram ter se apaixonado através do contato virtual, 15 buscaram contato real, com os parceiros virtuais (71\%) e desses 15 , 13 chegaram a ter relacionamento sexual real com esses parceiros antes virtuais. Esse sem dúvida é um índice bastante alto (87\%) que esperamos seja comprovado mais adiante quando a pesquisa estiver mais adiantada.

Ainda em relação a busca de contato sexual real, é comum que muitos usuários da Internet utilizem os chats como veículo para detectar possíveis parceiros para uma relação sexual genital. Freqüentemente estes iniciam conversas nas salas de bate-papo perguntando dados que indiquem a disponibilidade ou não de um encontro real, como por exemplo de onde a pessoa está digitando. Quando da mesma localidade, a investigação passa a ser pelo grau de disponibilidade emocional (estado civil) e pelos atributos físicos (sexo, cor dos olhos, dos cabelos, idade, altura e peso). Quando o internauta se interessa pela descrição, inicia uma conversa sedutora que pode culminar no "sexo virtual" (troca de mensagens que suscitam uma relação sexual genital) e depois na tentativa de marcar um encontro real. Este tipo de usuário praticante de "sexo virtual" é bastante comum na Rede e diante de suas expectativas e objetivos a Internet propicia que encontrem facilmente uma demanda grande de pessoas que buscam a mesma aproximação. Isto é facilitado já que muitos sites e chats são categorizados como de "sexo virtual" ou de prática sexual específica (homossexuais, casais, sadomasoquismo, etc.) e portanto supõe-se que os usuários estejam ali com objetivos similares.

Temos visto que, em qualquer dos aspectos que abordemos, a "potencialidade" suscitada pelo ambiente virtual parece-nos ponto de similaridade. Quando discutimos por exemplo a questão do anonimato que a Internet possibilita*, cremos que se uma mulher se coloca como homem em uma conversa, através da adoção de um nickname masculino por exemplo, também ela está atuando uma "potencialidade" de sua sexualidade, muito embora ela não seja realmente homem sob o ponto de vista anatomo-fisiológico. Se esta mesma mulher está na verdade experimentado sua homossexualidade, sua fantasia sexual ou exercitando sua criatividade, só sabere-

\footnotetext{
* A questão do anonimato também permite que questionemos a validade das pesquisas realizadas online, já que não há como prever se o sujeito está realmente descrevendo dados reais que podem ser de interesse para a pesquisa, como aqueles identificatórios: sexo, idade, grau de instrução, entre outros.
} 
mos se a tomarmos como objeto de estudo individualizado. O fato é que há muitos internautas que estão experimentando estas suas potencialidades, alguns mesmo utilizando a Internet como forma saudável de expressarem desejos e realizarem fantasias que sentem ser difíceis de se efetuarem na vida concreta. No entanto há, como já lembramos, pessoas que não conseguem estipular bem um limite para a experimentação, correndo o risco de estabelecerem uma grande lacuna entre as fantasias e as possibilidades de concretização no plano real.

Outro ponto relevante para a discussão sobre o sexo virtual é aquele referente a ética das relações humanas e outros valores que implicam as noções de cidadania. No potencial do mundo virtual os limites estão pouco claros. Se tomarmos o exemplo acima citado, o da mulher que se faz passar por homem em um bate-papo, como fica o outro usuário que crê estar conversando mesmo com um homem? E se começa a envolver-se afetivamente por este "homem"? Muitos internautas afirmam com veemência que as pessoas que freqüentam os chats tendem a ser mais sinceras porque tem garantido o seu anonimato e por isso podem expressar sua tristeza, defeitos, virtudes e alegrias com maior liberdade. Não creio que isto ocorra de forma integral. Da mesma forma que no encontro real acionamos determinados mecanismos que promovem atitudes porque desejamos ser aceitos pelo outro, ou mesmo seduzir alguém, no espaço virtual a palavra é utilizada com este fim. É traço característico das conversas virtuais o bom humor, a graça, a descontração, comportamentos estes observáveis na vida cotidiana é verdade, mas com bem menos freqüência que aquela encontrada no espaço virtual. É fácil encontrar alguém na Rede que esteja disponível a uma boa conversa para relaxar, com quem eu possa trocar novas informações, para quem eu e meu discurso sejam totalmente uma novidade. Será que conseguimos ser interessantes todos os dias com quem convive conosco, que já conhece muitas de nossas inquietações a e atitudes? Claro que não e isto faz parte da vida cotidiana de todos nós e também da disposição interna de cada um para aceitar com prazer o corriqueiro e entusiasmar-se com a renovação. Para aqueles que consideram os relacionamentos virtuais mais interessantes que os reais, fica aqui a sensação da "mascarada", do exercício da virtualidade da personalidade que pode afastar o indivíduo de sua verdadeira condição humana.

Gostaria de voltar a questão da ética, já que outro tema importante se apresenta e tem sido alvo de constantes discussões. A divulgação de imagens de crianças e púberes em poses eróticas e mesmo em ato sexual explícito com adultos é freqüente na Internet, embora seja proibida e prevista em lei pena para o infrator. Muitas dessas fotos que já tivemos a oportunidade de observar e que são veiculadas e trocadas em chats a qualquer hora do dia ou da noite, são perceptivelmente caseiras e a questão que me pergunto é em quais condições essas crianças foram submetidas para ser assim fotografadas? Teriam sido forçadas por pessoas mais velhas, muitas vezes os 
próprios os pais ou este comportamento já faz parte de sua realidade vidas intra-familiar? Mesmo que algumas crianças possam experimentar sensações prazerosas no contato sexual com um adulto, muitas vezes este prazer associa-se à culpa e reverte-se em sofrimento psíquico. O sexo passa a ser encarado, mais tarde como um misto de prazer e dor. Isto sem contar outras conseqüências da relação sexual adulto/criança citadas em diversos estudos que enfocam este tema: traumas físicos, incluindo lacerações vaginais e anais, infecções e doenças venéreas; desordens menstruais; distúrbios de sono e alimentação; dificuldade de aprendizagem; sentimentos de ódio em termos do agressor e do parente não agressor; fugas do lar, uso do álcool e de drogas; prostituição juvenil subsequente, etc. (Azevedo; Guerra, 1988).

Nesse caso cabe em nossa reflexão se é salutar deixarmos, em nome da potencialidade do sexo virtual, que muitas crianças estejam expostas a essas conseqüências deletérias na sua vida afetivo-sexual. A legislação Brasileira condena a divulgação de qualquer tipo de material erótico que envolva crianças ou adolescentes. Segundo o artigo 241 do estatuto da criança e do Adolescente há previsão de um a quatro anos de reclusão a quem registre, divulgue ou publique cenas de sexo explícito envolvendo crianças e adolescentes. O difícil tem sido descobrir os responsáveis por estes sites. Porque justamente por estarem infringido uma lei, mudam seus endereços virtuais a todos os instantes. No entanto a tecnologia também está a serviço das corporações policiais, dos poderes legislativo e judiciário e tem ajudado neste ponto. Em outubro de 1999, a Promotoria pública do Rio de Janeiro conseguiu fazer uma blitz antipedofilia, apreendendo equipamentos de informática de 27 pessoas que, segundo as investigações, eram responsáveis pela divulgação de cenas de sexo envolvendo crianças e adolescentes na Internet. Segundo os noticiários, os equipamentos (computadores, disquetes, CD-ROMs, etc.) foram encontrados em (...) casas de família de classe média alta, entre elas as de médicos, empresários, administradores de empresas, militares e até de um pastor evangélico (Jornal Folha de $S$. Paulo - $3^{\circ}$ caderno - 23 de outubro de 1999). Em março deste ano outra pessoa foi presa em Curitiba por vender CD-ROMs com imagens de crianças bem pequenas em poses percebidas como "eróticas" ou "sensuais".

Há também um fator importante a ser registrado que é o da receptividade dos internautas para a prática desta "pedofilia virtual". Talvez o anonimato e a potencialidade virtual da pulsão sexual já discutida neste texto, viabilize a infração do tabu mais antigo e forte, encontrado em quase todas as sociedades desde a antigüidade: $o$ tabu do incesto. A relação incestuosa interdita, que tem maior incidência no vínculo entre pais e filhas, tanto no plano real quanto no plano da fantasia, parece estar encontrando, na virtualidade do sexo, uma forma projetiva de ser violada.

Ainda em relação a propagação de material pornográfico, também os serviços de prostituição tem se utilizado da Internet para facilitar a aproximação com os clientes. Muitas mulheres que prestam serviços sexuais estão 
preferindo colocar suas fotos e serviços sexuais em homepages. Para elas o uso da Rede como forma de propaganda tem possibilitado quebrar a dependência dos agenciadores que intermediam este tipo de negociação. Além disso, segundo essas mulheres, elas evitam a exposição do corpo em locais públicos, diminuem o risco da violência, aumentam os lucros e podem, de alguma forma "escolher" seus clientes. Estes são sem dúvida pontos interessantes para nossa reflexão que envolve as vertentes éticas que compõem o uso da Internet, da globalização e da conseqüente revolução tecnológica dos costumes.

Em relação a educação, também a sexualidade está, no mundo virtual, oferecendo alternativas. Como os sites da Sociedade Brasileira de Sexualidade Humana (SBRASH) e do Centro de Estudos PERSONA que oferecem informações científicas, e fóruns de discussões sobre os temas afeitos à sexualidade humana, muitas entidades que tem o mesmo objetivo estão dispondo seus serviços de orientação na Rede. Este é sem dúvida um avanço que a Internet possibilita as sociedades, já que a qualquer hora do dia, ou da noite qualquer pessoa em qualquer lugar que tenha acesso a um computador "plugado" na Internet pode satisfazer suas duvidas e obter informações sobre sexualidade. Desta forma muitos mitos e crendices sexuais podem ser desfeitos e outras desinformações aplacadas. Algumas instituições escolares no Brasil já se utilizam da Internet como instrumento de acesso a informações científicas na área da sexualidade humana.

No entanto, há também um outro lado. Da mesma forma que os internautas tem acesso aos sites de prestação de serviço de cunho educativo, também tem a mesma facilidade para acessar outros sites que tenham um apelo erótico explícito. E a discussão envolve agora como os pais devem orientar as crianças a seriar os sites que seriam ou não adequados a elas no "ciberespaço". Pensamos que se faz imprescindível discutir a livre divulgação de mensagens que chegam nos correios eletrônicos fazendo propaganda de sites eróticos. Pode parecer repressiva a idéia de limitar o tipo de mensagem que pode ou não ser enviada a revelia do usuário, no entanto é importante pensar que uma garota ou um garoto de 4 ou 5 anos pode encontrar e-mails em sua caixa postal que convidam à visitação de um site de prática sexual explícita e específica, como os de bestialismo, sadomasoquismo, exibicionismo, ou outro qualquer.

Exibicionismo e voyeurismo me parecem duas formas de comportamento sexual que se complementam e tem encontrado, na Internet solo fértil para sua realização. $\mathrm{O}$ jogo das relações se estabelece comumente entre aquele que exibe suas idéia, sua sedução e seu corpo através de imagens ou frases digitadas para aqueles que as captam em silêncio; ou ainda para outros que competem na exibição e assim reasseguram uma posição por vezes narcísica. A imagem refletida de Narciso no lago é correlata ao espelho da Madrasta de Branca de Neve e hoje pode ter seu referencial na tela de um monitor. Mas embora tenha também o narcisismo tornado um produto a ser 
consumido em nossa sociedade, que nos dizeres de Caridade tem se transformado na (...) a sociedade do espetáculo (Caridade, 1999), nem este na atualidade pode desfrutar do prazer de ver refletido nos olhos dos outros a imagem enebriante do corpo que faz malabarismos, que dança, contorce, endurece, que chora e ri. O show da virtualidade do sexo nas telas dos computadores não me parece tão atrativo quanto o espetáculo da vida. E neste ponto eu concordo com Martha Medeiros quando diz: Alguém pode escrever com raiva, escrever com dor, escrever com ironia, escrever com dificuldade, escrever apressado, escrever na obrigação, escrever com segundas intenções. Nada disso chegará do outro lado da tela: a pressa, a hesitação, a tristeza. As palavras chegarão desacompanhadas. Será preciso confiar no talento do remetente em passar emoção junto de cada frase. Como pouquíssimas pessoas têm esse dom uma mensagem sensível poderá ser confundida com secura, tudo porque faltou um par de olhos, faltou um tom de voz. (...) Amor virtual é legal, mas o teclado ainda não dá conta de certas sutilezas. (Medeiros, 2000)

\section{BIBLIOGRAFIA}

AZEVEDO, M. A.; GUERRA, V.N. Pele de Asno não é só história... São Paulo, Roca, 1988.

CARIDADE, A. Sexualidade e saúde emocional, Revista Brasileira de Sexualidade Humana, Vol. 9:2. São Paulo, Iglu, 1998.

CADERNOS DE INFORMÁTICA do Jornal Folha de S. Paulo.

FERREIRA, A. B. de Holanda Mini Dicionário Aurélio da língua portuguesa. Rio de Janeiro, Nova Fronteira, 1993.

FREUD, S. Três ensaios sobre sexualidade e outros trabalhos, Obras completas, Volume VII. Rio de Janeiro, Imago, 1989.

HANNS, L. A teoria pulsional na clínica de Freud. Rio de Janeiro, Imago, 1999.

LAPLANCHE, J.; PONTALIS, J-B. Vocabulário de Psicanálise. São Paulo, Martins Fontes, 1986.

LÉVY, P. O que é virtual? São Paulo, Editora 34, 1999.

MEDEIROS, M. Por trás das palavras in Poesias e outras reflexões, http:// www.egroups.com/docvault/lingua_portuguesa

NICOLACI-DA-COSTA, A. M. Na malha da Rede. Rio de Janeiro, Editora Campus, 1998. 